\section{Carnivores in living colour}

\section{The Big Cats and Their Fossil Relatives: An Illustrated Guide to Their Evolution and Natural History}

by Mauricio Antón and Alan Turner Columbia University Press: 1997. Pp. 256. $\$ 46, £ 31.95$

\section{Adrian M. Lister}

In this attractive book, the artist Mauricio Antón has collaborated with the palaeontologist Alan Turner to produce a persuasive account of an extraordinary group of animals. Turner's text is informative and scholarly, yet entertaining and accessible. But Antón's illustrations are the revelation, and certainly rank among the best reconstructions of extinct animals ever produced.

Here are the big cats, engaged in all manner of activities: courting, hunting, feeding or simply watching. The animals are truly alive on the page, whether in pencil drawing or full-colour painting. Antón has observed living cats acutely, compared their detailed anatomy with those of their fossil relatives, and re-created with exceptional empathy the extinct forms. The ways in which the details of soft anatomy, such as ears and lips, can be deduced from skeletal anatomy, and the limitations of such reconstructions, are explained in the text and make interesting reading.

After a brief description of early forms that paralleled the true cats - nimravids, creodonts and marsupial 'cats' - the true cats are treated more fully. The text introduces us to living and extinct forms in the same format and with equal weight, a device that adds to the sense of the fossils as real animals and effectively conveys the full diversity of the group. Turner wisely avoids the common obsession of making phylogeny the central theme of all palaeontological work, concentrating instead on diversity and adaptation. He summarizes questions of relationship and nomenclature with sensible pragmatism, pointing out that "we still lack any clear idea of the immediate ancestors of the living groups or of the precise pattern of relationships between them".

The two main groups of big cats are the Felinae, which have conical canines, and the wholly extinct Machairodontinae, or sabretooths. The authors describe different adaptive types based on the known ecology and behaviour of modern forms, and use these to deduce the locomotion (climbing versus running) and hunting (stalking versus ambush) strategies of the extinct forms from their anatomy.

The function of the sabre-toothed cats' distinctive flattened canines, which could be as long as 28 centimetres, has been much

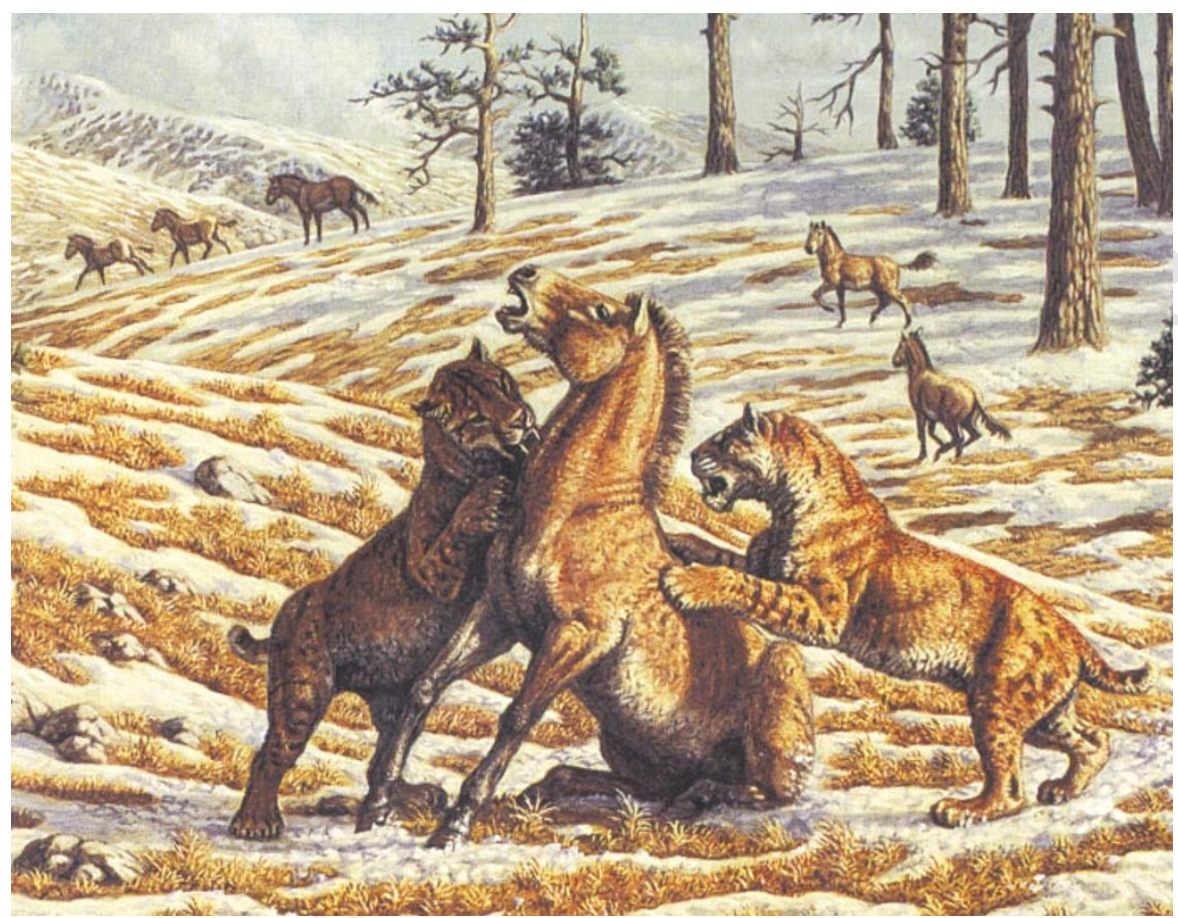

Double jeopardy: two young sabre-toothed cats risk their delicate upper canines in an ill-judged attack.

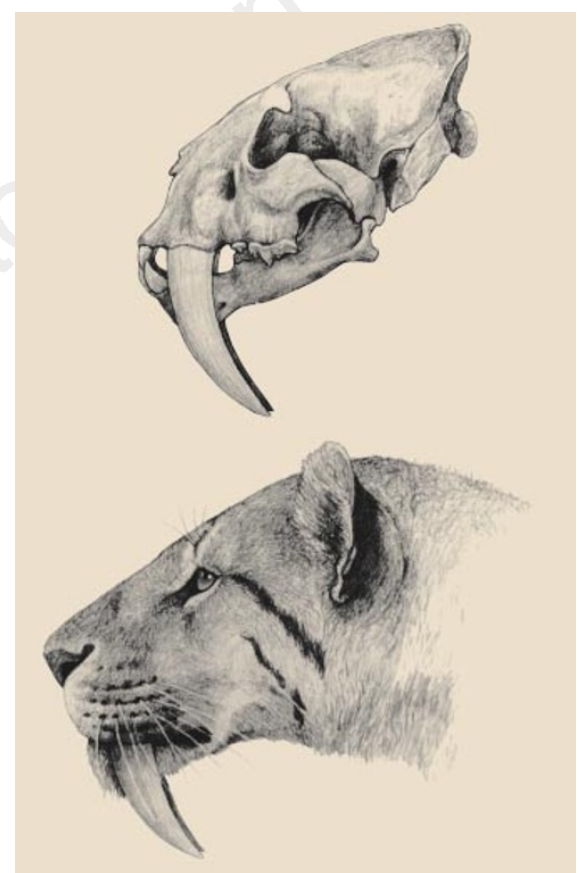

Fleshed-out feline: a reconstruction of the head of the American sabre-tooth Smilodon fatalis.

debated. Turner and Antón suggest that they were too delicate to be used on moving prey. Instead they argue that the sabre-tooths used their enormously powerful front quarters to pull the prey to the ground before biting. While the animal was held down to prevent it struggling, a carefully placed pierce or slash of the throat by the canines would have led to the prey bleeding to death, in contrast to the suffocating grip of modern big cats. The book's illustrations of the cats pursuing and dispatching their prey are especially wondrous, whether the cat is stalking with intent gaze, turning in a cloud of dust or caught in mid-pounce.

Even aspects of social structure (solitary or communal) can be deduced for extinct species, based on hunting strategy (from skeletal proportions), brain size and the composition of the fossil assemblage. But the authors are realistic about the limitations of such conclusions, especially given the flexibility exhibited by modern species.

In the final part of the book, Turner and Antón try to draw conclusions about episodes of evolution and extinction through geological time, and about the environmental forces that may have driven them. For these more contentious issues, the popular treatment is perhaps less satisfactory. For the first time, one feels the need to see the raw data to be persuaded by the arguments. Supposed extinction 'events' at 5, 2.5 and 0.9 million years ago seem to be somewhat extended in time, from the information given. But some hypotheses, if treated as such, are intriguing. For example, it is suggested that, between 2 and 3 million years ago, global cooling triggered the spread of more open, savannah habitats in Africa. This led to selection for swifter-running herbivores, favouring the feline cats at the expense of the sabre-tooths, which went into decline.

This is an outstanding book for both palaeontologist and 'neontologist' to relish. It should convince even those sceptical of the value of palaeontology that we live within a thin skin of biodiversity underlain by an extraordinary richness, which has much to teach us about evolution and its products. $\square$ Adrian M. Lister is in the Department of Biology, University College London, London WC1E 6BT, UK. 